\title{
The Creole Connection: What Happens Next?
}

Michael Lee Thomas, Georgia Southern University, USA

Linda Greef Mullen, Georgia Southern University, USA

\begin{abstract}
The purpose of this case is to demonstrate the importance of target market selection and positioning, particularly for businesses in small college towns. Additionally, other marketing and management issues are presented to stimulate understanding of the multitude of variables that impact restaurant success. This case is intended for those interested in marketing, management, entrepreneurship, hotel/restaurant management or retailing areas.
\end{abstract}

Keywords: Restaurant management, small business, entrepreneurship and target marketing

\section{INTRODUCTION}

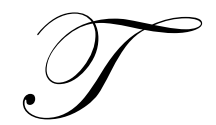

he Creole Connection is a locally owned bar/restaurant, featuring live entertainment that tries to appeal to all ages and backgrounds. The establishment is located in a small southern college town in the center of the downtown business district. While the bar area has attempted to cater to all including the college crowd, the location makes it difficult for students to get to and from the bar without driving. The establishment is not within walking distance of the College or other college bar/restaurants.

The business has enjoyed success for several years, but the last year and a half saw diminishing sales due to increased competition and other internal factors. An offer to sell was accepted, but when the buyer backed out, the business continued on the road to closure. After two months, the owner decided to reopen. The owner realizes that he has made some mistakes in the past and is interested in correcting and refocusing his efforts to make the Creole Connection a success.

\section{CREOLE CONNECTION OVERVIEW}

The building in which the Creole Connection resides is owned by the restaurant's proprietor, Jason Magg. The building's two other occupants are long standing, highly successful establishments. Gracie's Hair Salon is on the right of the restaurant and Bonnie Bests' Bakery is on the left. Parking is adequate for all, but becomes overcrowded during the bar's happy hour (all three establishments are open at this time). The Creole Connection has approximately 5,000 square feet of space, which the owner has designated as half for dining and half for bar/stage (see Figure 1 for restaurant layout). Capacity for the restaurant is approximately 175 people (seats 50 in the dining area).

The Creole/New Orleans theme is evident throughout the restaurant, including the exterior, interior décor, and extensive menu. Additionally, the menu offers standard American fare including steaks and burgers. Customers can choose from a wide variety of choices. The pricing is moderate to high for a meal. The restaurant serves both lunch and dinner. The establishment is open Monday through Saturday; the lack of Sunday liquor sales has caused them to remain closed on Sundays. The state has considered doing away with these blue laws, which would allow for Sunday openings, but nothing has materialized yet.

In the beginning, the food received high marks from patrons, but began to deteriorate due in part to heavy turnover among their chefs (four in last two years). Unfortunately, this decline in food quality coincided with an increase in menu prices. The dining patrons are predominately made up of couples and families. On the other side 
of the establishment, the bar patrons are comprised of regular, locals, college students, and businessmen/women (drop by on their way home from work). In addition to food and beverages, the Creole Connection offers live music, (usually on weekends and occasionally during the week). They feature local, regional, and occasionally national acts. Musical styles consist of acts from any genre including but not limited to Irish Folk, Country, and HipHop. The crowds on the band nights vary in demographics and numbers depending on the band booked. The Creole Connections has also sponsored "Sports Nights" showing a featured sporting event on their big television screen.

Figure 1 Restaurant Floor Plan

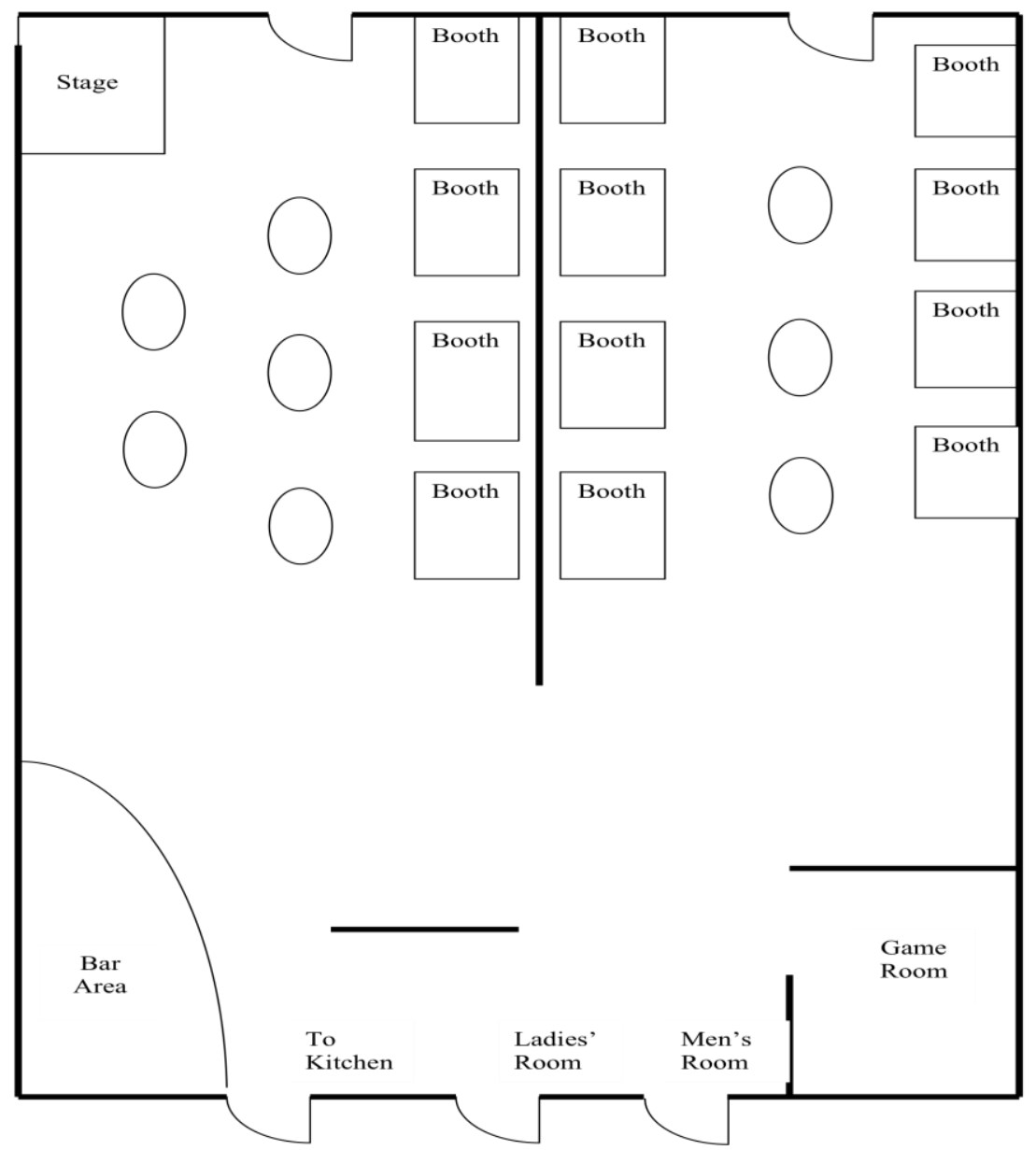

Competition is intense with seventy-five restaurants in the area. These range from small "mom and pop" establishments to national chains. Traditionally the market was dominated by fast food and moderately priced eateries. However, recent market entries include a higher-end regional steak house chain, two high-end steak/seafood establishments, a middle-tier Mexican restaurant, and a Caribbean-themed establishment (the Caribbean restaurant presents the most direct competition due to the similar nature in theme). Non-food bars are few with only 8 located in town. 
Table 1 provides demographic information for the county in which the business resides. County population is approximately 55,000 residents with an additional college population of 20,000. The citizenry is fairly equally split between males and females with a fairly high percentage of younger residents (over $73 \%$ under the age of 45 , not including college students). Racially, the populous is predominantly white $(68.7 \%)$ with a significant black population $(28.8 \%)$. The university has a similar racial makeup. Further, Table 1 gives the education and income breakdown for the county.

Table 1: County Demographics

\begin{tabular}{|lcc|}
\hline & $\mathbf{N}$ & Frequency (\%) \\
Gender & $\mathbf{5 5 , 9 8 3}$ & $\mathbf{1 0 0 . 0 0}$ \\
Male & 27,255 & 48.68 \\
Female & 28,728 & 51.32 \\
& & \\
Age & $\mathbf{5 5 , 9 8 3}$ & $\mathbf{1 0 0 . 0 0}$ \\
Under 18 & 12,480 & 22.29 \\
$18-24$ & 14,647 & 26.16 \\
$25-44$ & 13,893 & 24.82 \\
$45-64$ & 9,756 & 17.43 \\
65 and over & 5,207 & 9.30 \\
Race & & $\mathbf{1 0 0 . 0 0}$ \\
White & $\mathbf{5 5 , 9 8 3}$ & 68.70 \\
Black & 38,460 & 28.80 \\
Hispanic & 16,101 & 1.90 \\
Other & 979 & 0.10 \\
& 443 & \\
Education & & $\mathbf{1 0 0 . 0 0}$ \\
High school or higher & $\mathbf{2 8 , 7 4 0}$ & 77.94 \\
Bachelor's degree or higher & 22,400 & 25.41 \\
Note: education stats & 7,303 & \\
include only 25 yrs. and older & & \\
& & $\mathbf{1 0 0 . 0 0}$ \\
Household Income & & 34.82 \\
Less than \$20,000 & $\mathbf{2 0 , 7 5 7}$ & 21.67 \\
\$20,000 - \$34,999 & 7,228 & 14.74 \\
\$35,000 - \$49,999 & 4,498 & 14.68 \\
\$50,000 - \$74,999 & 3,060 & 7.21 \\
\$55,000 - \$99,999 & 3,047 & 5.68 \\
\$100,000 - \$199,999 & 1,497 & 1.20 \\
\$200,000 or more & 1,178 & \\
(Source: 2000 U.S. Census) & 249 & \\
& & \\
\hline
\end{tabular}

The owner, Jason Maggs manages all operations of the establishment, which includes kitchen staff, waiter/waitresses, hostesses and bar tenders (approximately 10 employees working at any one time). The owner controls all aspect of the operations and is present during all hours the business is open. He can be found to be moving throughout all of the positions depending on the need. This sometimes causes problems with the staff as they are reprimanded regularly by Mr. Maggs. Unfortunately, his management style has become increasingly aggressive - employees are regularly critiqued in front of other employees and customers. Employee turnover is high.

The original marketing plan was to target all local residents and students by advertising weekly in the local paper, university paper and on local billboards. Additionally, special promotions were developed including a local radio station was hired to run the "Battle of the Bands" contests. Creole Connection developed a grassroots "texting initiative" designed to reach regulars and other special interest groups in the local and college communities. One 
complaint from dining patrons is that bands playing frequently set up and do sound checks during the mealtime. The more mature diners have not always appreciated the excessive noise.

\section{CONCLUSION}

In conclusion, after the sale of the business fell through, the Creole Connection's sales and profits continue to deteriorate. Mr. Maggs felt he had no other choice but to close and hopefully another suitor to purchase would emerge. However, after three months of being closed and with no other offers to purchase, the owner now feels compelled to reopen. He believes the business should not be left dormant. Further, he is open to suggestions and advice on how to reopen Creole Connection and make it a more successful establishment. He has hired the reader to give him the solid planning he needs to make Creole Connection as successful as it once was.

\section{RECOMMENDATIONS FOR DISCUSSION}

\section{Who was the target market for the Creole Connection?}

Management has stated that they want to appeal to everyone. So, their target market is every resident, which includes local residents and college students. The reader should understand that this approach is known as a mass marketing approach.

2. Who do you think their target market should be? Why?

The reader who agree with the Creole Connection's past approach should be challenged to provide changes to the business's current marketing and management approaches given that the mass marketing approach was a failure. Perhaps, significant changes might make this approach more palatable. However, it should be pointed out that attempting to be everything to everyone is fraught with dangers. For example, businesses with low prices do not provide the highest level of product quality and service, as this tends to raise prices. Additionally, the discount approach limits the target market to those consumers who are more priceconscious and less style conscious. A better approach would be to choose to target either, the students and young locals, or to target older locals.

3. How does the demographic distribution of the county impact your decision? How does this county compare to national statistics?

The reader should notice that the even gender mix does not lend itself to any special attention. The racial distribution does present opportunities/threats given the predominant white and black populations. Bands directed at blacks or whites might present opportunities, but must be managed carefully not to alienate the other group. Additionally, the readers who focus on education and income statistics should provide data to show how this county differs from national statistics. Significant departures deserve special consideration. For example, highly educated communities might prefer activities that stimulate thought (i.e. trivia nights).

4. What are some examples of services/offerings that overlapped (or might have overlapped) with different customer groups?

Bands performing sound checks during dinner hours are an obvious example. The readers should be encouraged to think "outside the box" for other potential areas where trying to appeal to everyone might result in an alienation of multiple groups. For example, families might not want to have dinner at an establishment where college students are gathering for drinks. Additionally, students might prefer to patronize an establishment that doesn't have local families having dinner. 


\section{What would you focus on (if you were the owner) for the potential reopening? Should they reopen?}

The obvious answer is to choose a specific target market (i.e. the students or locals) and position the business to appeal to the chosen group. Other issues that should be addressed are the management style and competition. The reader should be encouraged to be creative to find opportunities to differentiate the Creole Connection from the competition. An example would be to focus on New Orleans themed events (the reader might even propose changing the theme). Additionally, the new competition, current economy and past mistakes might lead the reader to suggest not reopening. If this is the case, the reader should be prompted to provide suggestions for what the owners should do next (i.e. rent out the current location as they own the property).

\section{AUTHOR INFORMATION}

Michael Lee Thomas, Ph.D. is an Assistant Professor of Marketing in the College of Business at Georgia Southern University. His research focuses on Retail and Retail Management and marketing nonprofits. His teaching interests include Retail, Business Marketing and Strategic Management. He received his Ph.D. in Marketing from Southern Illinois University, Carbondale in 2007.

Linda Greef Mullen, Ph.D. is an Assistant Professor of Marketing in the College of Business at Georgia Southern University. Her research focuses on White Collar Crime, Sales and Sales Management, and pedagogy issues. Her teaching interests include Professional Sales, Sales Management and Strategic Management. She received her Ph.D. in Marketing from Southern Illinois University, Carbondale in 2005. 


\section{NOTES}

